Revista Brasileira de Farmacognosia Brazilian Journal of Pharmacognosy 22(5): 1060-1069, Sep./Oct. 2012

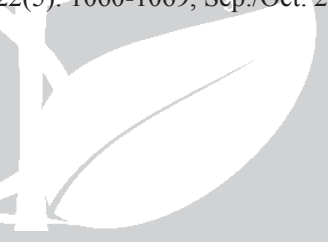

Article

Received 2 Feb 2012

Accepted 21 Apr 2012

Available online 16 Aug 2012

Keywords:

electron microscope

Ginkgo biloba

kidney

VEGF

ISSN 0102-695X

http://dx.doi.org/10.1590/S0102-

695X2012005000093

\section{Therapeutic dose of Ginkgo biloba extract 761 may alter the urine excretion of Wistar rats}

\author{
Monica S. C. Dalmacio, ${ }^{*, 1}$ Sylvia M. N. Campos, ${ }^{2,3}$ Jorge J. J. \\ Carvalho, ${ }^{4}$ Mário J. S. Pereira, ${ }^{4}$ Ana Lúcia Nascimento, ${ }^{4}$ Patricia \\ O. Paschoal, ${ }^{2,5}$ Andrea P. Sobrinho, ${ }^{2}$ Monique M. B. Pedruzzi, ${ }^{2,3}$ \\ Valeria Garrido, ${ }^{2}$ Silvana R. F. Moreno, ${ }^{1,6}$ Gerlinde A. P. B. \\ Teixeira, ${ }^{2,3}$ Gilberto P. Cardoso ${ }^{1}$
}

\author{
${ }^{1}$ Programa de Pós-graduação em Ciências Médicas, Hospital Universitário Antônio \\ Pedro, Universidade Federal Fluminense, Brazil, \\ ${ }^{2}$ Departamento de Imunologia, Instituto de Biologia, Hospital Universitário Antônio \\ Pedro, Universidade Federal Fluminense, Rio de Janeiro, Brazil, \\ ${ }^{3}$ Programa de Pós-graduação em Patologia, Hospital Universitário Antônio Pedro, \\ Universidade Federal Fluminense, Brazil, \\ ${ }^{4}$ Departamento de Histologia e Embriologia, Universidade do Estado do Rio de \\ Janeiro, Brazil, \\ ${ }^{5}$ Programa de Pós-graduação em Pediatria, Hospital da Criança, Universidade do \\ Estado de São Paulo, Brazil, \\ ${ }^{6}$ Departamento de Patologia, Hospital Universitário Antônio Pedro, Universidade \\ Federal Fluminense, Rio de Janeiro, Brazil.
}

\begin{abstract}
Wistar rats $(\mathrm{n}=20)$ were divided in two groups: $\mathrm{G} 1$ received $2 \mathrm{mg} / \mathrm{kg}$ of GBE (Ginkgo biloba extract 761), whereas G2 received the same volume of a sodium chloride solution $(0.9 \%)$, both for 10 days. After a 7 -day interval, the treatment was repeated for 8 days. Urine volume and food and water intake were measured daily during this protocol. Histological assessments were performed. No significant difference $(p>0.05)$ was observed in food and water intake of animals during treatment with GBE. Animals who received GBE had a smaller urine volume and increase of weight with a significance difference $(p<0.05)$ during the first and second exposure period. No histological alteration was observed in tissues, except for the kidney of the experimental group, which revealed a higher concentration of red cells in the glomerulus with a strong staining for Vascular Endothelial Growth Factor (VEGF). The introduction of GBE (therapeutic dose) in health rats may promote alterations in the physiology of the kidney, but no sufficient to modify the glomerulus architecture, including at ultra structural level (electron microscopy).
\end{abstract}

\section{Introduction}

The Ginkgo biloba L. (Gb) tree is genus Ginkgo is in the family Ginkgoaceae, is one of the world's oldest living species, dating back more than 200 million years (Major, 1967).

The standardized dry extract from G. biloba extract $761(\mathrm{GBE})$ is obtained through an acetone-water extraction followed by subsequent purification steps with no addition of concentrates or isolated ingredients. The raw material for pharmacopeia grade GBE consists of the dried leaf of G. biloba, is characterized by: 22$27 \%$ flavones glycosides, determined as quercetin (1) and kaempferol (2), including isorhamnetin (3) (via HPLC) and calculated as flavones with a molar mass of $\mathrm{MMr}=756.7$ (quercetin glycosides) and $\mathrm{Mr}=740.7$ (kaempferol glycosides); $5-7 \%$ terpene lactones, of which approximately $2.8-3.4 \%$ consists of ginkgolides A (4), B and C, as well as approximately $2.6-3.2 \%$ bilobalide (5); below 5 ppm ginkgolic acids (British Herbal Medicine, 1996).

Botanical identity confirmation through a thinlayer chromatography (TLC) test, as well as macroscopic and microscopic examinations of the medicinal plant are mandatory (British Herbal Medicine, 1996) and, the British Herbal Pharmacopoeia requires that the dried leaf of GBE contains no less than $18 \%$ water-soluble extractive (British Herbal Medicine, 1996). It has described that both the acute and chronic toxicity of this extract is very low ( Blumenthal \& Busse, 1998).

Although the German Commission E recommends that doses from 120 up to $240 \mathrm{mg} /$ day 
<smiles>[R]c1cc(-c2oc3cc(O)cc(O)c3c(=O)c2O)ccc1O</smiles>

$1 \mathrm{R}=\mathrm{H}$

$2 \mathrm{R}=\mathrm{OH}$

$3 \mathrm{R}=\mathrm{OCH}_{3}$

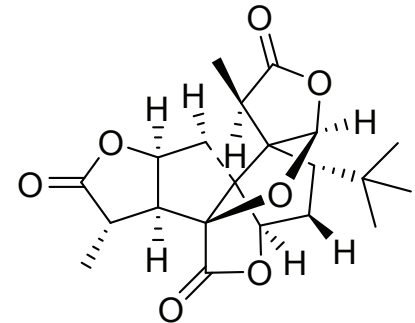

4

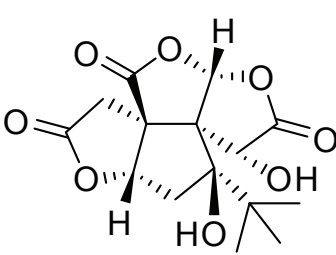

5 of the GBE should be taken twice or three times a day for cerebral insufficiency (Blumenthal \& Busse, 1998), typical doses vary from 120 to $160 \mathrm{mg} /$ day for others treatments (Valli \& Giardina, 2002; Kudolo et al., 2005; Tang et al., 2007). Common side effects described are: nausea, dyspepsia, headache and allergic skin reactions. More serious adverse effects have been identified, including spontaneous subdural hematomas, intracerebral hemorrhage, as well as warfarin and trazodone interactions (Valli \& Giardina 2002).

In humans, ginkgolide $\mathrm{B}$ is a potent inhibitor of PAF (Platelet-Activating Factor), a biologically active phospholipids mediator involved in acute inflammatory immunological responses which has been intimately linked to reperfusion injuries and cardiac dysfunction in shock. Other components of GBE have been identified as inhibitors of phospholipase $\mathrm{A}_{2}$, thus inhibiting the production of PAF and eicosanoids (Valli \& Giardina, 2002).

In the kidney, mesangial cells can synthesize and secrete a contract protein factor and PAF, which regulates the structure and the function of the glomerulus. Moreover, alteration of the function of this cell is central to the progression of glomerulus disease in numerous models of chronic renal failure (Wang et al., 2006). This suggests a role for PAF in the accumulation of mesangial matrix, which occurs during glomerulosclerosis while secretion of PAF by the epithelial cells inhibits proteoglycan production (Ruiz-Ortega et al., 1998).

Podocytes or visceral epithelial cells are highly differentiated glomerulus cells which cover GBM (Glomerulus Basement Membrane). They are unable to replicate, forming a filtration slit structure that avoid the protein to escape into urine. Considerable evidence in experimental animals indicates that disruption of podocytes contributes to the development of glomerulus sclerosis (Macedo et al., 2007).

Thus, the objective of this study was to evaluate the effects of a GBE (therapeutics dose): (i) on the weight, on the food and water intake and the urinary excretion and (ii) on the organs morphology (liver, spleen and kidneys; targeting the organs most affected by potentially toxic or injury.

\section{Materials and Methods}

\section{Chemicals and reagents}

A commercial standardized mixture GBE, obtained (Farmacutis, Niteroi, RJ, Brazil), from Jiangsu Medicines and Health Products, lot No. GB002123, China, was used. In order to determine the concentration of water soluble chemical components, a solution of GBE was prepared by diluting $3.6 \mathrm{~g}$ of the powder contained in the GBE capsules in $9 \mathrm{~mL}$ of $9 \%$ physiologic $\mathrm{NaCl}$. The percentage of extract of the capsule that is soluble in $0.9 \%$ saline was $24.66 \mathrm{mg}$. The soluble extract in saline was not filtered.

Having determined the concentration of the water soluble chemical components of GBE, and based on the clinical doses used for humans (120 mg/day), a fresh solution was prepared daily and immediately before its administration to the animals. Each animal received $2 \mathrm{mg} / \mathrm{kg}$ once a day according to the individual weight and the experimental design (Teske \& Trentini, 1995; Moreno et al., 2007).

\section{Experimental animals}

Adult (3-5 months) female Wistar rats $(\mathrm{n}=20)$ weighing 320-380 g were obtained and maintained in metabolism cages. They were given free access to food and water in a temperature-controlled room (25 ${ }^{\circ} \mathrm{C}$ ) with a $12 \mathrm{~h}$ light/dark cycle, the percentage with relative humidity in the environment of experimental was the $60 \%$.

Rats were randomly assigned to the experimental/ $\mathrm{Gb}$ and control groups (G1 and G2 respectively). During the first exposure period to GBE $\left(1^{\text {st } E}\right)$ animals of $G 1$ 
received a daily $2 \mathrm{mg} / \mathrm{kg}$ dose of GBE by the oral rout for ten days and we observe any kind of metabolism alterations. This period was followed by a 7-day rest to observe if occurs metabolism changes post treatment. The animals finally received another cycle of a daily $2 \mathrm{mg} / \mathrm{kg}$ dose of GBE by the oral rout for 8 days $\left(2^{\text {nd }} \mathrm{E}\right)$ to confirm if really happenings metabolism alterations in the treatment with GBE. During both the first and second exposure periods, animals of G2 received an equivalent volume of $0.9 \%$ saline solution by the oral rout. This research received approval by the animal ethics committee at the School of Medicine of the Fluminense Federal University under the 0040/08 registration number.

\section{Food and water intake and animal weight control}

Food and water intake were monitored on a daily basis for the 25 days of this protocol for both groups. An excess of Purina ${ }^{\circledR}$ rat chow was weighed and offered to the animals, and after $24 \mathrm{~h}$ of free consumption, the leftover diet was weighed and the result was expressed as milligrams of food per gram of body weight per day ( $\mathrm{mg} / \mathrm{gbw} /$ day). In the same manner, excess volume of water was offered to the animals during the 25 days of this protocol. After $24 \mathrm{~h}$ of free consumption, the leftover water was measured and the result was expressed as milliliters of water intake per day. The urinary volume was measured daily during the entire experimental period. All animals were weighed at the beginning and at the end of the experiment.

\section{Histomorphology}

After the necropsy, kidney, spleen and liver of all animals were fixed in $10 \%$ buffered formaldehyde and stained with hematoxylin and eosin (HE) to verify the presence of any histological alterations.

\section{Immunohystochemistry}

To perform immunohystochemistry, a standard immunoperoxidase technique was used with formalin fixed paraffin embedded tissue sections ( $5 \mu \mathrm{m}$ thickness) and mounted on silanized slides. To identify laminin distribution after blocking of endogenous peroxidase activity, slides were incubated with mouse antihuman laminin for $20 \mathrm{~min}$, washed with PBS, incubated with biotinylated rabbit antimouse antibody for $30 \mathrm{~min}$, and followed by the peroxidase conjugated streptavidin antibody at room temperature. Finally, slides were incubated with diaminobenzidine (DAB) at room temperature and then counterstained with haematoxylin.

To evaluate the VEGF (Vascular Endothelial Growth Factor) and the Smooth Muscle $\alpha$-actin (SM $\alpha$ A) tissues sections were blocked with $3 \%$ bovine serum albumin (BSA) in PBS, incubated with primary antibody for $2 \mathrm{~h}$, and treated with LSAB2 system horseradish peroxidase (HRP) according to the manufacturers' recommendations. Finally, the samples were incubated with diaminobenzidine (DAB) at room temperature and counterstained with haematoxylin.

\section{Transmission electron microscopy}

Fragments of kidney were fixed in 2.5\% glutaraldehyde diluted in $0.1 \mathrm{M}$ sodium cacodylate buffer $\mathrm{c}(\mathrm{pH}$ 7.2). After fixation, the fragments were washed in the same buffer and then post-fixed for $60 \mathrm{~min}$ at room temperature in $1 \%$ osmium tetroxide $\left(\mathrm{OsO}_{4}\right)$ solution containing $0.8 \%$ potassium ferricyanide in $0.1 \mathrm{M}$ cacodylate. After fixation, the cells were washed in the same buffer and thereafter, were dehydrated in a graded series of acetone and embedded in epoxy resin. Ultrathin sections were stained with uranyl acetate and lead citrate, and then examined with an EM 906 Zeiss transmission electron microscope.

\section{Statistical analysis}

Data is expressed as mean $\pm \mathrm{SD}$. The program Graph-Pad InStat 4.01, by Graphpad Software Inc ${ }^{\circledR}$, was used to determine the minimum significance difference using ANOVA with Fisher's or Tukey's post-test. It was considered a statistical significance when $p<0.05$.

\section{Results}

\section{Weight analysis}

All rats were weighed immediately before the first exposure of GBE and at the end of the second GBE exposure. The mean weight of the experimental/Gb(G1) and control group (G2) was $333.46 \pm 12.22 \mathrm{~g}$ and $373.20 \pm 14.22$ $\mathrm{g}$ respectively at the beginning of the protocol (Figure 1). Both groups showed a significant increase in body weight, although the control group presented a smaller significance $(p=0.023)$ when compared to the experimental group $(p=0.001)$. When analyzing the mean weight gain of each group at the end of the assay, a significant difference $(p<0.05)$ was also observed. Animals of the experimental group gained a mean of $18.76 \mathrm{~g}$ while the control group gained a mean of $10.46 \mathrm{~g}$.

\section{Food and water consumption}

Evaluation of food and water intake of both $\mathrm{G} 1$ and $\mathrm{G} 2$ groups during the 25 days of the protocol $\left(1^{\mathrm{st}} \mathrm{E} /\right.$ Rest $/ 2^{\text {nd }} E$ ) was performed. During the three stages of the protocol, it was not observed significant differences in the consumption of food between G1 ( ${ }^{\mathrm{st}} \mathrm{E}: 21.08 \pm 1.72 \mathrm{~g}$; 
PR: $\left.21.43 \pm 0.57 \mathrm{~g} ; 2^{\text {nd }} \mathrm{E}: 21.91 \pm 0.88 \mathrm{~g}\right)$ and $\mathrm{G} 2(1 \mathrm{stE}$ : $21.59 \pm 1.17 \mathrm{~g}$; PR: $\left.21.03 \pm 1.31 \mathrm{~g} ; 2^{\text {nd }} \mathrm{E}: 21.44 \pm 2.04 \mathrm{~g}\right)$ (Figure 2).

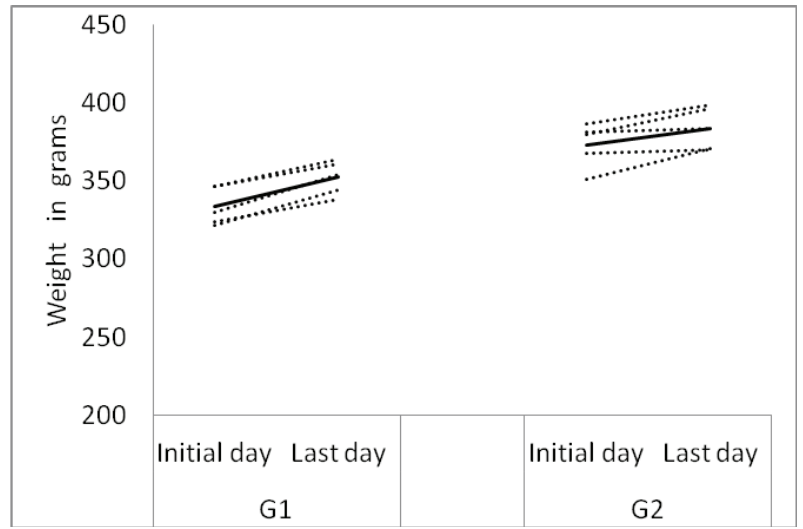

Figure 1. Behavior of individual and mean body weight throughout the experiment $(\ldots .$.$) weights (-)$ mean of the group. Weight increasing of $2.75 \%$ for the control group (G2) $(p=0.023)$ and $5 \%$ for the experimental/Gb (G1) $(p=0.001)$.

When evaluating the consumption of water during the same period, no differences between the groups were observed (Figure 3). The means for the three experimental periods were presented in Table 1.
Table 1. Mean food intake by five animals during the three experimental periods ( $\left(1^{\text {st }} \mathrm{E}, \mathrm{PR}\right.$ and $\left.2^{\text {nd }} \mathrm{E}\right)$.

\begin{tabular}{lccc}
\hline \multicolumn{1}{c}{ First GBE Exposure } & $\mathrm{G} 1$ & $\mathrm{G} 2$ & $p$ value \\
& $20.96 \pm 1.77 *$ & $21.57 \pm 1.23$ & 0.092107 \\
\hline Physiological rest & $21.55 \pm 0.61$ & $21.13 \pm 1.23$ & 0.081144 \\
Second GBE exposure & $21.91 \pm 0.88$ & $21.44 \pm 2.04$ & 0.492324 \\
\hline * mg/gbw/ day & & &
\end{tabular}

\section{Urinary excretion}

When analyzing each period separately, our results demonstrate an interference of GBE on the urinary system of the rats. During the first and second periods of exposure, the mean urinary volume of the ten animals pertaining to G1 (experimental/Gb) is significantly smaller $(0.228 \pm 0.068 \mathrm{~mL} /$ day $)$ than that of the media of the animals of G2 $(0.259 \pm 0.076 \mathrm{~mL} /$ day) $(p=0.0246)$ with a reduction the $11,97 \%$ when compared a control group. When the GBE treatment was interrupted an inversion occurs and animals of G1 (experimental $/ \mathrm{Gb}$ ) present a significantly larger urinary volume $(p=0.000151)(0.17 \pm 0.010 \mathrm{~mL} /$ day $)$ than that the animals of $\mathrm{G} 2(0.15 \pm 0.001 \mathrm{~mL} /$ day $)$ with a smaller daily variation $(p<0.01)$. With the reintroduction $\left(2^{\text {nd }} E\right)$ of GBE, the urinary volume differs between the groups again $(p=0.003162)$ with a reduction in urine volume in

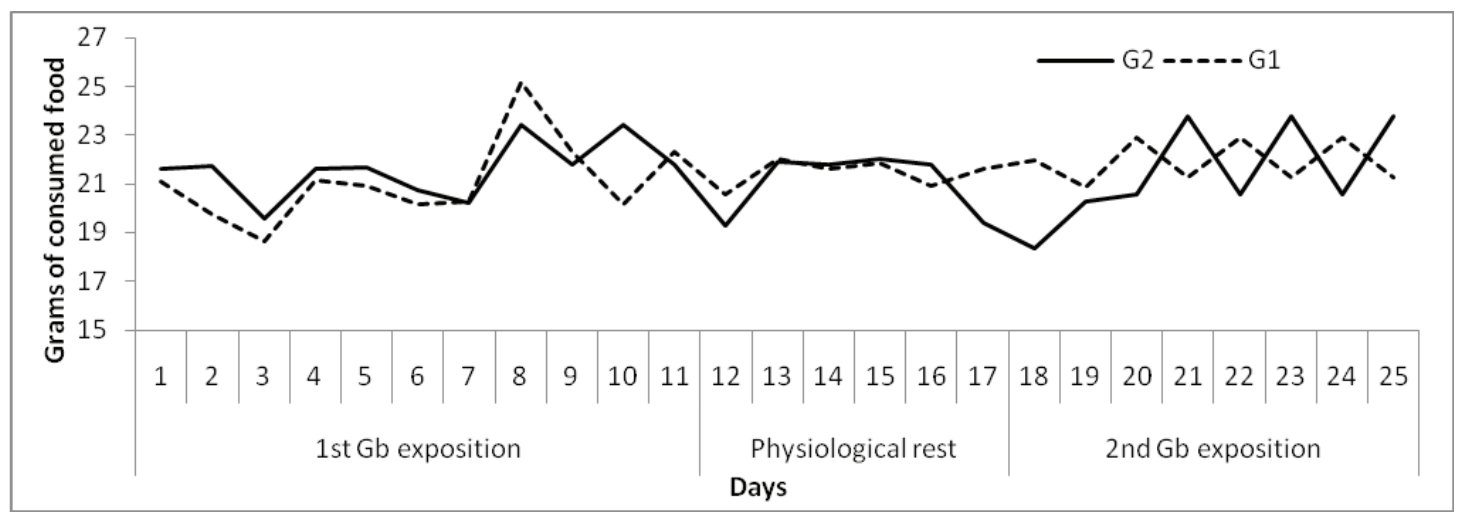

Figure 2. Daily mean food intake of the media/animals of each group.

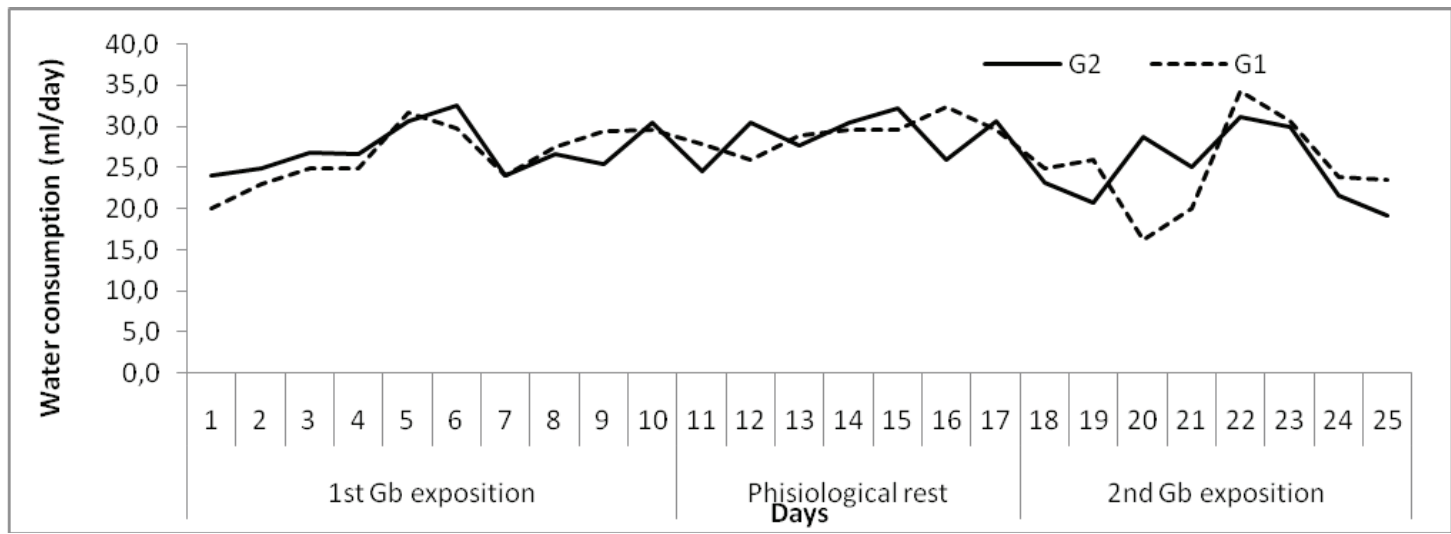

Figure 3. Daily mean water consumption of the animals of each group. 
the experimental/Gb group.

The analysis of the kinetics of the urinary flow shows a significant decrease in the urinary volume between the first and tenth day of the protocol for G1 group. On the $11^{\text {th }}$ day, the urinary volume of G1 (experimental/ $\mathrm{Gb}$ ) presented a slight increase and maintained stable up to the 18th day, when the GBE was reintroduced $\left(2^{\text {nd }} \mathrm{E}\right)$. During this period, animals of G2 (control) presented a urinary volume similar to that of the end of the $1^{\mathrm{st}} \mathrm{E}$ period. During the second GBE exposure, a reduced of the mean urinary volume was observed in G1, whereas animals of G2 presented little variation, maintaining levels of urinary flow with a significant decrease (Figure 4).

\section{Histomorphology}

Comparing the microscopic morphology of the spleen of animals pertaining to G1 and G2, no alterations were observed in the white or red pulp, in the vascular system or in primary follicles (Figure 5). Likewise, no alteration was observed in the vascular (arteries and veins) or cellular (hepatocytes) structure of the liver (Figure 6). On the other hand, when examining the kidney, animals pertaining to G1 presented vascular congestion of the glomerulus and tubules (Figure 7).

\section{Immunohystochemistry}

To check the integrity of blood vessels and the presence of angiogenesis in the kidney, immunohystochemistry assays to the basement membrane and smooth muscle were performed. Results were negative for $\mathrm{SM} \alpha \mathrm{A}$ in the kidney samples of both G1 and G2, and no vascular lesion or any other tissue alterations were present in the samples of the two groups (Figure 8)

Staining kidney sections of animals pertaining to G1 (experimental/Gb) and G2 (control) for lamimin showed the integrity of basal membrane with no differences at the glomeruli or tubules (Figure 9). However, staining was positive to VEGF in kidney sections of G1, but not of G2 (Figure 10). The darker areas seen in sections of G1 indicate a Vascular Endothelial Growth (light alteration), which was not observed in control animals.

\section{Transmission electron microscopy}

In treated animals with GBE, Glomerulus Basemen Membranes and Podocytes presented similar architecture to the control animals (Figure 11).

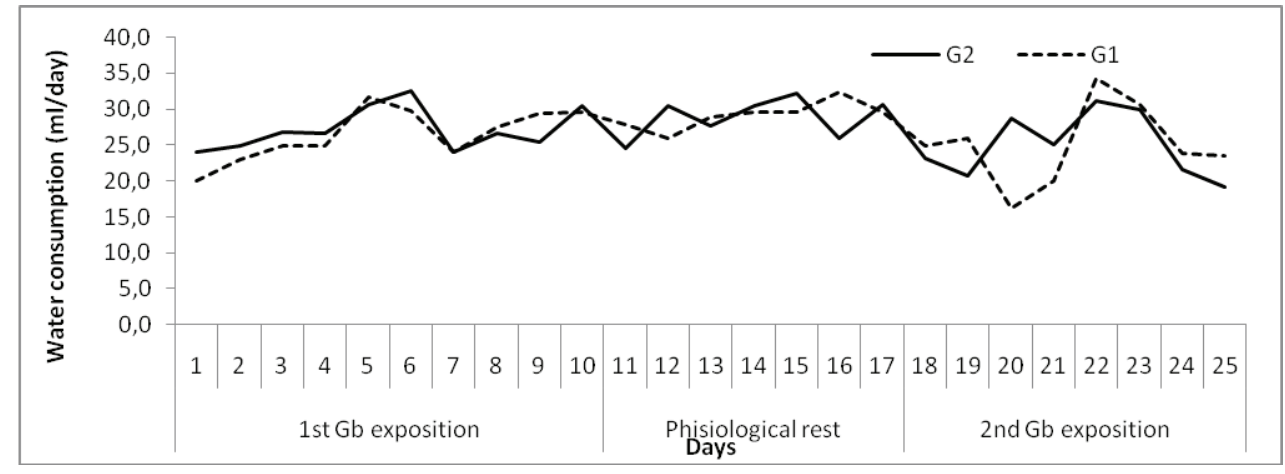

Figure 4. Daily mean water consumption of the animals of each group.
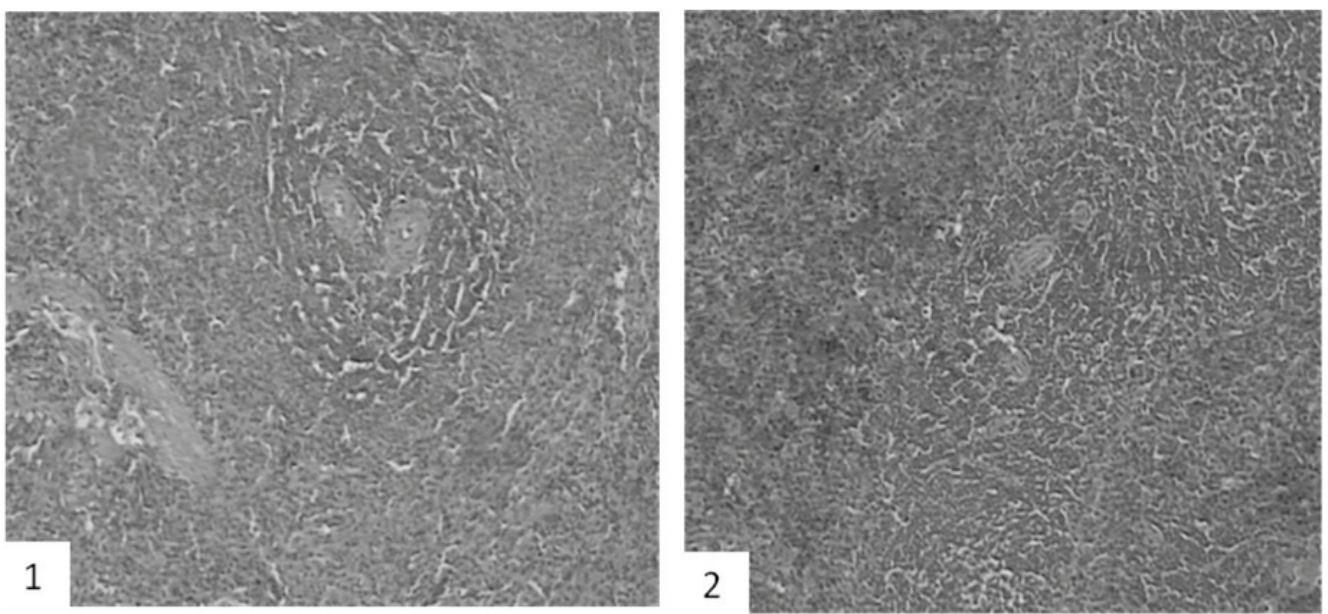

Figure 5. Photomicrography of spleen (20x). 1. Experimental/Gb animals (G1); 2. Control animals (G2). We cannot see the any alterations in the concentration of red cells in the groups experimental or control. 

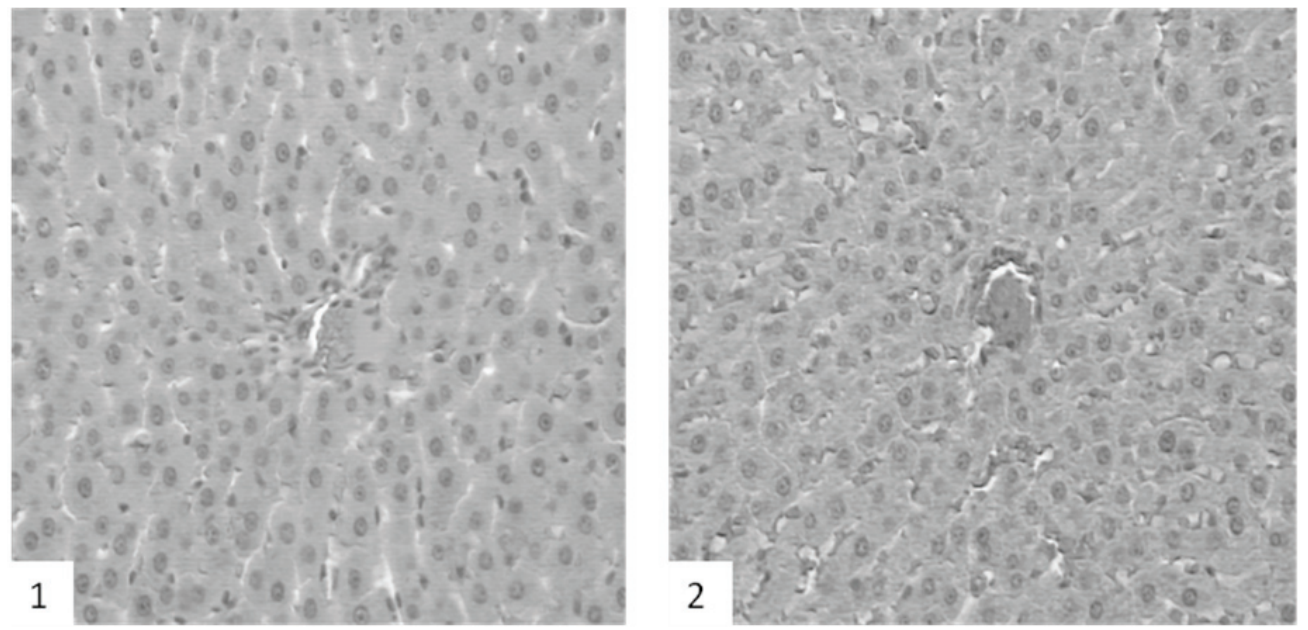

Figure 6. Photomicrography of liver (20x). 1. Experimental/Gb animals (G1); 2. Control animals (G2). We cannot see any alterations in the hepatic cells or arterial structure in both groups.
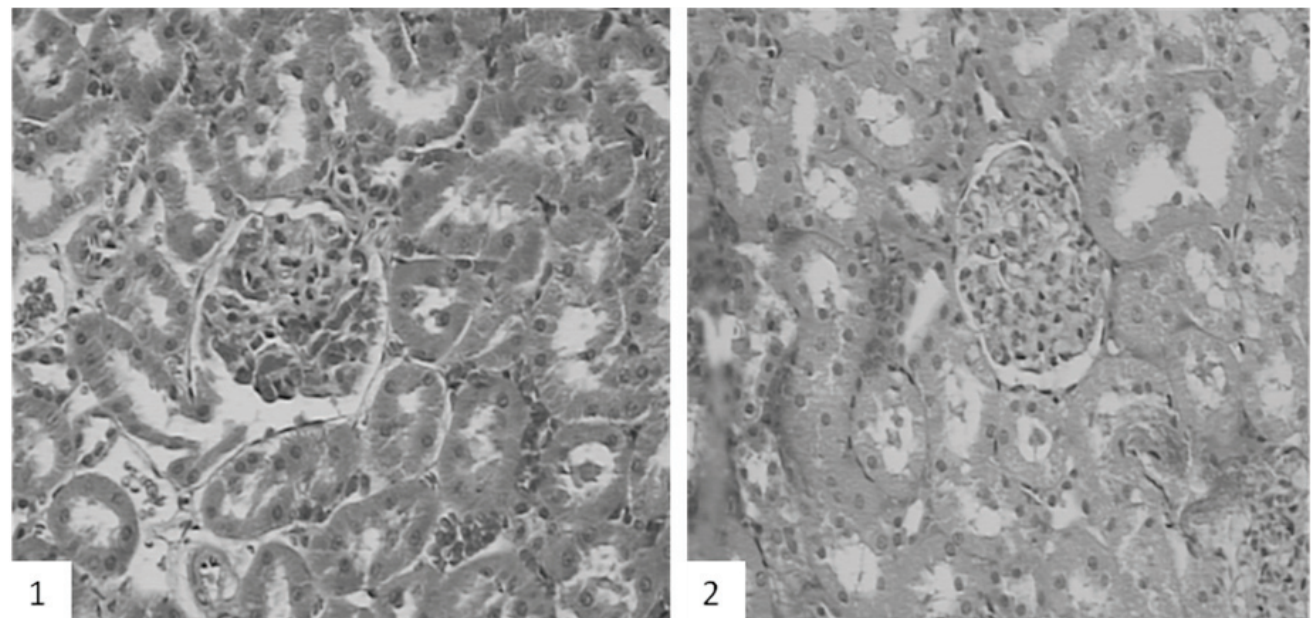

Figure 7. Photomicrography of kidney (20x). 1. Experimental/Gb animals (G1); 2. Control animals (G2). We can see the concentration of red cells in the G1 are superior than the control group.
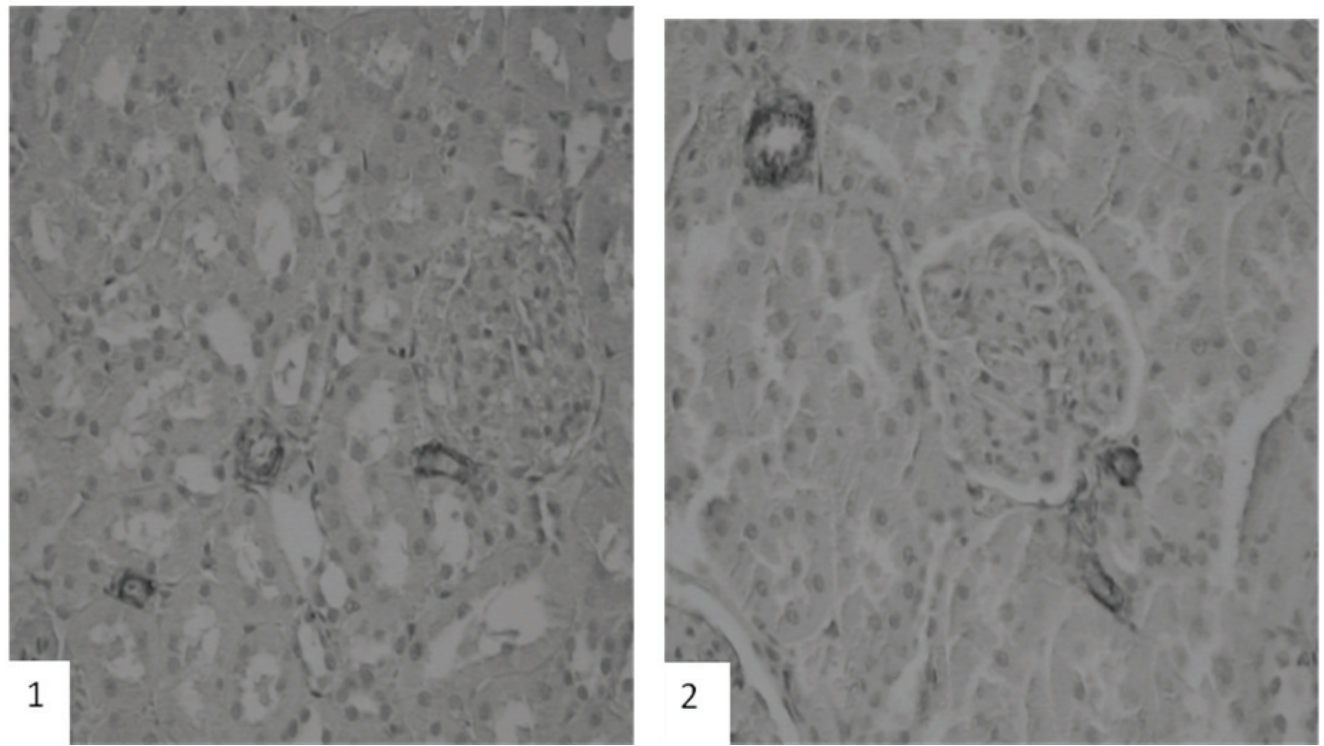

Figure 8. Photomicrography of kidney (20x). Immunohystochemistry smooth muscle $\alpha$-actin. 1. Experimental/Gb animals (G1); 2. Control animals (G2). No differences in the arterials integrity in both groups. 

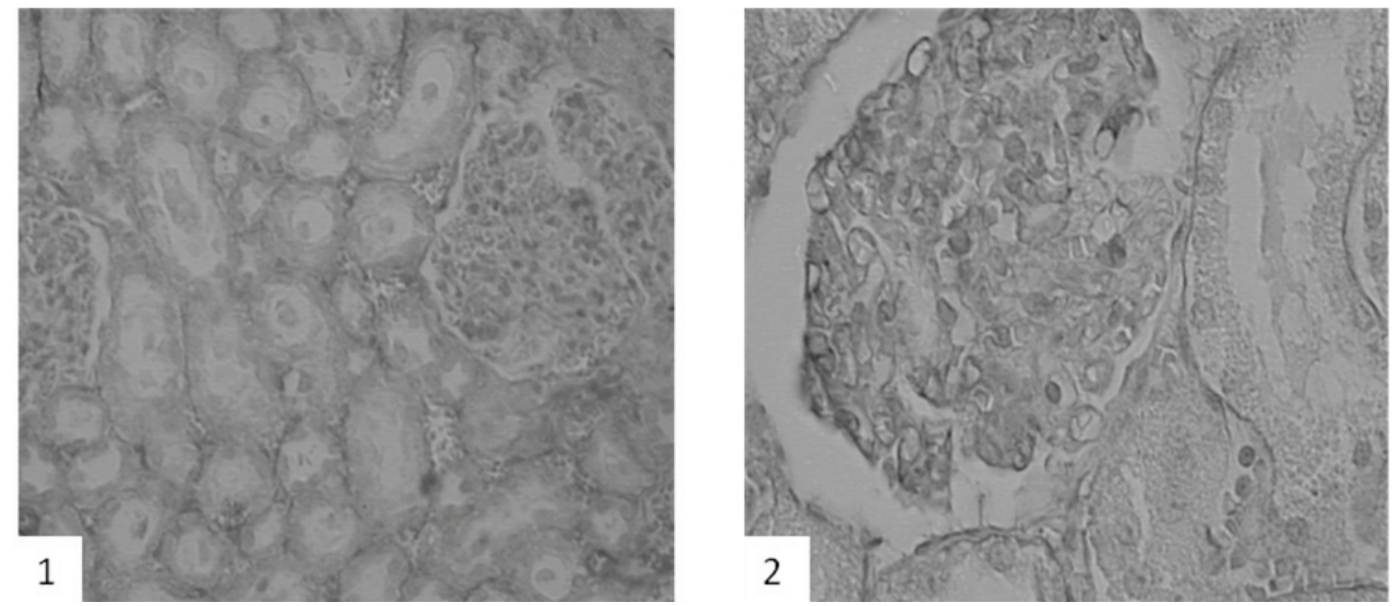

Figure 9. Photomicrography of kidney (40x). Immunohystochemistry, laminin.

1. Experimental animals/Gb (G1); 2. Control animals (G2). No differences in the membrane structures in the both groups.
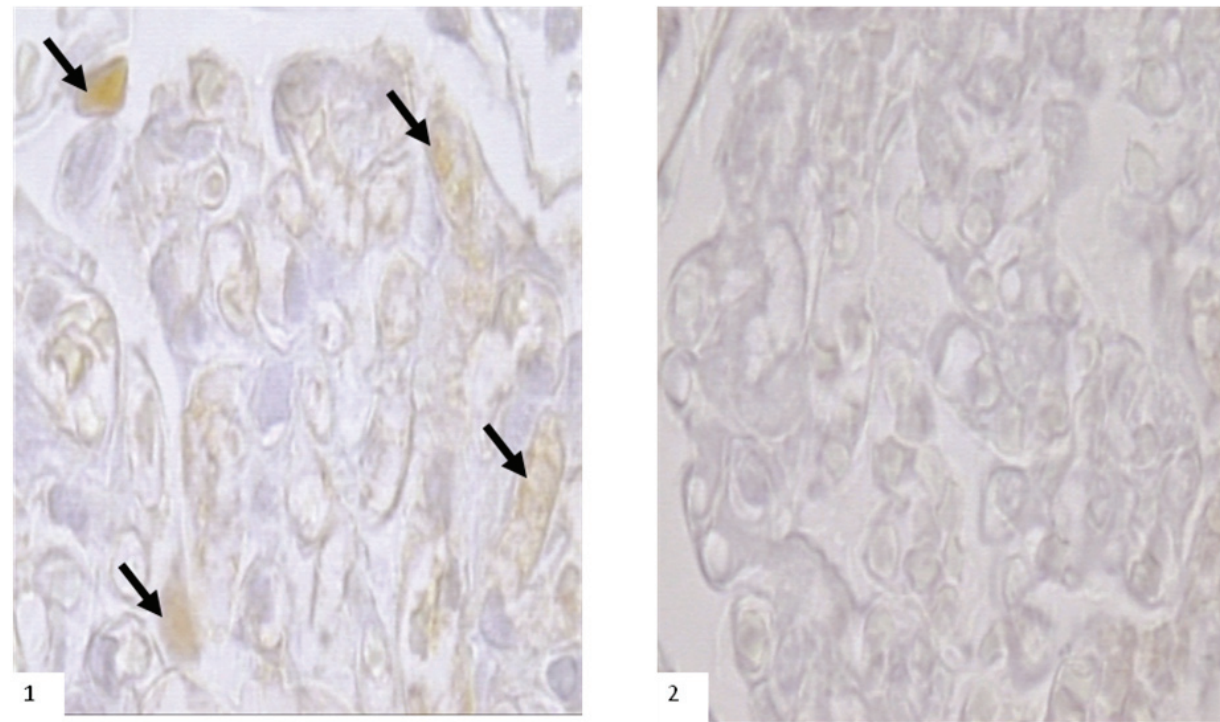

Figure 10. Photomicrography of kidney (20x). Immunohystochemistry VEGF (vascular endothelial growth factor). 1. Experimental/ Gb animals (G1); 2. Control animals (G2). In the control group we cannot observe the presence of VEGF as we can see in the GBE group with the fixed color. There is a positive staining to the VEGF in experimental group (panel 2) when compared to the control animals (panel 1).
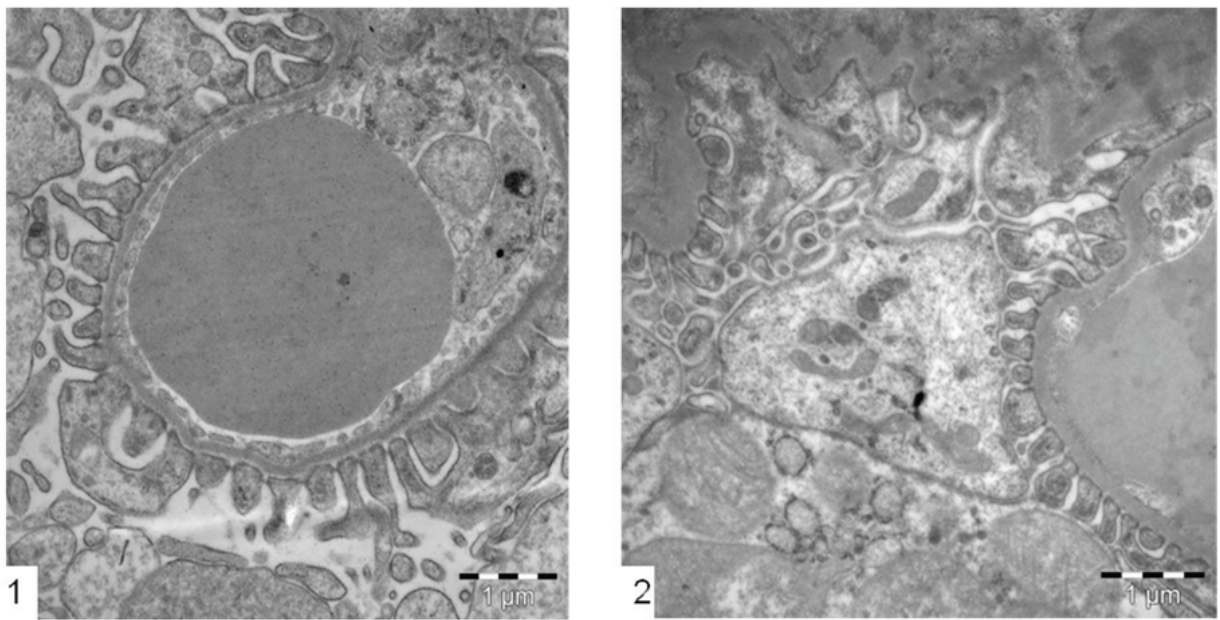

Figure 11. Group experimental/Gb (1) and Control (2) with 16700x showing healthy endothelium with pedicels and podocytes. 


\section{Discussion and Conclusion}

Although GBE has been reported in the traditional Chinese medicine as an adjuvant in weight reduction (Tian et al., 2004), our results do not confirm this finding. In our experiment, animals that received GBE for a total of eighteen days presented a significantly higher mean weight gain $(18.76 \mathrm{~g})$ when compared to the control group (10.46 g) during this period. Tian et al. (2004), examined 31 Chinese medicinal herbs used in weight reducing prescriptions of Traditional Chinese Medicine, and found that the inhibitory potencies of the active components of tuber fleece flower root, parasitic loran thus, green tea leaf and Ginkgo biloba leaf were similar to or greater than cerulenin and C75 (Pizer et al., 1998; Loftus et al., 2000; Kreider et al., 2010). It is possible to suggest that the treatment with GBE does not interfere in the weight gain or in the normal development of lean young animals.

Our data indicate that the kidneys of the animals submitted to the GBE treatment showed a more intense hematoxylin eosin (HE) coloring than the control animals, suggesting that some type of changes in histoarchitecture could be taking place. To elucidate these changes, it was performed the renal section to immunohystochemical assays, evaluating $\mathrm{SM} \alpha \mathrm{A}$, laminin and VEGF. No staining was observed for the first two antibodies (SM $\alpha \mathrm{A}$ and laminin), indicating that GBE either does not interfere. During normal development, $\mathrm{SM} \alpha \mathrm{A}$ is expressed in mesangial cells and is down regulated to a minimal expression in normal adult cells (Takeji et al., 2006). The only alteration observed in our histological analysis other than the more intense HE staining of kidneys pertaining to $\mathrm{G} 1$ (experimental $/ \mathrm{Gb}$ ) was the immunohistochemical staining for VEGF. Two processes may lead to blood vessel production: vasculogenesis and angiogenesis. Both the promotion and the reduction of angiogenesis have been reported with the use of GBE (Sun et al., 2009; Trompezinski et al., 2010).

Sun et al. (2009) reported that the GBE exerts protective effect on secondary cerebral ischemic injury after Sub Arachnoids Hemorrhage via the promotion of the expression of VEGF. On the other hand, Trompezinski et al. (2010) showed that GBE exerts a potent inhibition on VEGF levels in activated cells. GBE down regulates VEGF and IL-8 (interleukin 8) levels in a cumulative manner in Tumor necrosis factor- $\alpha(\mathrm{TNF} \alpha)$-stimulated normal human keratinocytes. Thus, Trompezinski et al. (2010) suggests that GBE may contribute to moderate the inflammatory processes in skin diseases associated with angiogenesis.

Rodriguez de Turco et al. (1993) presented data indicating that GBE inhibits stress-induced polydipsia in rats due to the stress of daily handling and intubation; whereas Porsolt et al. (1990) show that the repeated administration of GBE inhibits emotional hypophagia in mice due to the anxiolytic-like activity of this herb. In the study performed by Rodriguez de Turco et al. (1993) the GBE was dissolved in 5\% ethanol and control animals received equivalent volumes of $5 \%$ ethanol alone. In our model, feeding or drinking was not altered by GBE although weight gain was been larger significant for the G1 (experimental/Gb) $(p=0,001)$

More insights into the regulation of the kidney function can provide not only a better understanding of pathophysiological processes, but also eventually, the development of new therapeutic approaches (Vallon et al., 2006). On a recent search of the specific literature there were less than ten references which appeared upon a cross-search using "nephrotoxicity" and Ginkgo biloba as keywords. All papers showed that this herb is beneficial and protects the kidney from nephrotoxic substances such as uranium (Yapar et al., 2010), adriamycin (AbdEllah \& Mariee, 2007), cisplatin (Fukaya \& Kanno, 1999; Gulec et al., 2006), gentamicine (Naidu et al., 2000), and vancomycin (Celik et al., 2005). On the other hand, some herbal medications have potentially harmful side effects, as well as adverse interactions with prescription drugs (Qato, 2008). Despite the widespread concurrent use of conventional and alternative medicines, documented drug-herb interactions are sparse (Rai, 2004; Sparreboom et al., 2004; Zlotogorski \& Littner, 2004; Yale \& Glurich, 2005).

Renal excretion of fluid and electrolytes are under the control of a systemic neurohumoral system that plays a central role in body homeostasis (Atherton, 1972). Their fine control is regulated by specific factors and hormones such as arachidonic acid and its active metabolic products, which can modulate hemodynamic homeostasis (Feraille \& Doucet, 2001). In the kidney, the eicosanoids, active products derived from arachidonic acid, not only regulate inflammatory processes, but also have the potential to regulate the kidney (Mullins et al., 2006). The PAF causes increased vascular permeability in several tissues and so how GBE (containing the ginkgolides) can cause reduced loss of water (Wang et al., 2006).

One of the properties anti-inflammatory in vivo of GBE is through the inhibition of Thromboxane-2 (TXB2) synthesis (Kudolo et al., 2004). The GBE also shows a potent antioxidant in both normo-and hypercholemic subjects, possibly by inhibiting cyclooxygenases-1 (COX-1) isoform activity. Collectively, these data suggest that GBE is comparable to acetylsalicylic acid in terms of the inhibition of TXB2 and COX-1 (Kudolo et al., 2004). Attention of the side effects of conventional AINE'S (Non-steroidal anti-inflammatory drugs) including gastrointestinal and renal toxicity (Son et al., 2005).

GBE has a preventive effect on the expressions 
of inducible nitric oxide synthase and cyclooxygenase- 2 via suppression of nuclear factor-kappaB in RAW 264.7 cells induced by lipopolysaccharide stimulation. One of the molecules derived from Ginkgo biloba leaves, a biflavone known as Ginkgetin, inhibits cyclooxygenases-2 and 5-lipoxygenase in mouse bone marrow-derived mast cells (Son et al., 2005; Park et al., 2006).

The importance of the cyclooxygenases pathways in the control of blood pressure is illustrated by the use of AINE'S in humans, which inhibit both cyclooxygenases 1 or 2 isoforms and cause $\mathrm{Na}^{+}$ retention and hypertension. COX-1 is constitutively expressed in a variety of tissues, including the kidney (Cheng \& Harris, 2004). Probably, our data could be explained by the inhibitory effects of GBE on the COX and PAF pathway of arachidonic metabolism, but future researches are necessary, to prove this possibilities.

Another point that needs attention in the clinical setting is the fact that older populations are the main consumers of GBE and others prescription drugs. Despite concerns about drug safety, current information on both the use of prescription and over-the-counter medications, and dietary supplements is limited. Among prescription medication users, concurrent use of overthe-counter medications was $46 \%$ with a concurrent use of dietary supplements by $52 \%$ of the survey population (Qato et al., 2008). The fact of GBE promote reduction in the urinary volume it is possible to suggest that this extract may influence on the depuration time and to prolong the exposition time of drugs, consequently, affecting drug-herb interactions, but future researches are necessary, to prove this possibilities. The limitation of my study was no all questions were answers and we need future studies should look at measuring PAF, COX-1 and TXB2 to probably explain the reduced urinary volume. Avail what would have happened if we had treated the rats for a longer or shorter time period.

Concluding, as GBE may promote alterations in volume of the urine excretion. The introduction of GBE (therapeutic dose) in healthy rats may promote alterations in the physiology of the kidney, but no sufficient to modify the glomerulus architecture, including at ultra-structural level.

\section{Reference}

Abd-Ellah MF, Mariee AD 2007. Ginkgo biloba leaf extract (GBE 761) diminishes adriamycin-induced hyperlipidaemic nephrotoxicity in rats: association with nitric oxide production. Biotechnol Appl Bioc 46: $35-40$.

Atherton JC 1972. Renal physiology. Br J Anaesth 44: 236245.

Blumenthal M, Busse W 1998: The complete German commission E monographs: Therapeutic guide to herbal medicines. Boston: American Botanical Council.

British Herbal Medicine Association 1996. Scientific committee. British herbal pharmacopoeia. London. British Herbal Medicine Association.

Celik I, Cihangiroglu M, Ilhan N, Akpolat N, Akbuluty HH 2005. Protective effects of different antioxidants and amrinone on vancomycin-induced nephrotoxicity. Basic Clin Pharmacol 5: 325-332.

Cheng HF, Harris RC 2004. Cyclooxygenases, the kidney, and hypertension. Hypertension 3: 525-530.

Feraille E, Doucet A 2001. Sodium-potassiumadenosinetriphosphatase-dependent sodium transport in the kidney: hormonal control. Physiol Rev 1: 345-418.

Fukaya H, Kanno H 1999. Experimental studies of the protective effect of Ginkgo biloba extract (GBE) on cisplatin-induced toxicity in rats. Nippon Jibiinkoka Gakkai Kaiho 102: 907-917.

Gulec M, Iraz M, Yilmaz HR, Ozyurt H, Temel L 2006. The effects of Ginkgo biloba extract on tissue adenosine deaminase, xanthine oxidase, myeloperoxidase, malondialdehyde, and nitric oxide in cisplatin-induced nephrotoxicity. Toxicol Ind Health 3: 125-130.

Kreider RB, Wilborn CD, Taylor L, Campbell B, Almada AL, Collins R, Cooke M, Earnest CP, Greenwood M, Kalman DS, Kerksick CM, Kleiner SM, Leutholtz B, Lopez H, Lowery LM, Mendel R, Smith A, Spano M, Wildman R, Willoughby DS, Ziegenfuss TN, Antonio J 2010. ISSN exercise \& sport nutrition review: research \& recommendations. J Int Soc Sports Nutr 7: 1-44.

Kudolo GB, Delaney D, Blodgett J 2005. Short-term oral ingestion of Ginkgo biloba extract (GBE 761) reduces malondialdehyde levels in washed platelets of type 2 diabetic subjects. Diabetes Res Clin Pr 68: 29-38.

Kudolo GB, Wang W, Barrientos J, Elrod R, Blodgett J 2004. The ingestion of Ginkgo biloba extract (GBE 761) inhibits arachidonic acid-mediated platelet aggregation and thromboxane B2 production in healthy volunteers. J Herb Pharmacother 4: 4-13.

Loftus TM, Jaworsky DE, Frehywot GL, Townsend CA, Ronnett GV, Lane MD, Kuhajda FP 2000. Reduced food intake and body weight in mice treated with fatty acid synthase inhibitors. Science 288: 2379-2381.

Macedo CS, Lerco MM, Capelletti SM, Silva RJ, Pinheiro DO, Spadella CT 2007. Reduction of podocytes number in late diabetic alloxan nephropathy: prevention by glycemic control. Acta Cir Bras 22: 337-341.

Major RT 1967. The ginkgo, the most ancient living tree. The resistance of Ginkgo biloba L. to pests accounts in part for the longevity of this species. Science 794: 1270-1273.

Moreno SR, Carvalho JJ, Nascimento AL, Pereira M, Rocha EK, Olej B, Caldas LQ, Bernardo-Filho M 2007. 
Experimental model to assess possible medicinal herb interaction with a radiobiocomplex: qualitative and quantitative analysis of kidney, liver and duodenum isolated from treated rats. Food Chem Toxicol 45: 1923.

Mullins LJ, Bailey MA, Mullins JJ 2006. Hypertension, kidney, and transgenics: a fresh perspective. Physiol Rev 2: 709-746.

Naidu MU, Shifow AA, Kumar KV, Ratnakar KS 2000. Ginkgo biloba extract ameliorates gentamicin-induced nephrotoxicity in rats. Phytomedicine 3: 191-197.

Park YM, Won JH, Yun KJ, Ryu JH, Han YN, Choi SK, Lee KT 2006. Preventive effect of Ginkgo biloba extract (GBE) on the lipopolysaccharide-induced expressions of inducible nitric oxide synthase and cyclooxygenase-2 via suppression of nuclear factorkappaB in RAW cells. Biol Pharm Bull 5: 985-990.

Pizer ES, Chrest FJ, DiGiuseppe JA, Han WF 1998. Pharmacological inhibitors of mammalian fatty acid synthase suppress DNA replication and induce apoptosis in tumor cell lines. Cancer Res 20: 46114615 .

Porsolt RD, Martin P, Lenègre A, Fromage S, Drieu K. 1990. Effects of an extract of Ginkgo Biloba (GBE 761) on learned helplessness and other models of stress in rodents. Pharmacol Biochem Be 36: 963-971.

Qato DM, Alexander GC, Conti RM, Johnson M, Schumm P, Lindau ST 2008. Use of prescription and over-thecounter medications and dietary supplements among older adults in the United States. JAMA-J Am Med Assoc 24: 2867-78.

Rai J, 2004. Adverse interactions between low-dose aspirin/ warfarin and garlic/ginseng/Ginkgo biloba. Indian Heart 2: 176.

Rodriguez de Turco EB, Droy-Lefaix MT, Bazan NG 1993. GBE 761 inhibits stress-induced polydipsia in rats. Physiol Behav 53: 1001-1002.

Ruiz-Ortega M, Lorenzo O, Egidio J 1998. Angiotensin III up-regulates genes involved in kidney damage in mesangial cells and renal interstitial fibroblasts. Kidney Int Suppl 68: S41-45.

Son JK, Son MJ, Lee E, Moon TC, Son KH, Kim CH 2005. Ginkgetin, a biflavone from Ginko biloba leaves, inhibits cyclooxygenases-2 and 5-lipoxygenase in mouse bone marrow-derived mast cells. Biol Pharm Bull 12: 2181-2184.

Sparreboom A, Cox MC, Acharya MR, Figg WD 2004. Herbal remedies in the United States: potential adverse interactions with anticancer agents. J Clin Oncol 22: 2489-2503.

Sun BL, Hu DM, Yuan H, Ye WJ, Wang XC, Xia ZL 2009. Extract of Ginkgo biloba promotes the expression of
VEGF following subarachnoid hemorrhage in rats. Int $J$ Neurosci 7: 995-1005.

Takeji M, Moriyama T, Oseto S, Kawada N, Hori M, Imai E 2006. Smooth muscle alpha-actin deficiency in myofibroblasts leads to enhanced renal tissue fibrosis. J Biol Chem 52: 40193-40200.

Tang J, Sun J, Zhang Y, Li L, Cui F, He Z 2007. Herb-drug interactions: Effect of Ginkgo biloba extract on the pharmacokinetics of theophylline in rats. Food Chem Toxicol 12: 2441-2445.

Teske M, Trentini AMM 1995. Herbarium: Compêndio de Fitoterapia Curitiba: Herbarium Laboratório Botânico.

Tian WX, Li LC, Wu XD, Chen CC 2004. Weight reduction by Chinese medicinal herbs may be related to inhibition of fatty acid synthase. Life Sci 19: 2389-2399.

Trompezinski S, Bonneville M, Pernet I, Denis A, Schmitt D, Viac J 2010. Gingko biloba extract reduces VEGF and CXCL-8/IL-8 levels in keratinocytes with cumulative effect with epigallocatechin-3-gallate. Arch Dermatol Res 3: 183-189.

Valli G, Giardina EG 2002. Benefits, adverse effects and drug interactions of herbal therapies with cardiovascular effects. J Am Coll Cardiol 7: 1083-1095.

Vallon V, Mühlbauer B, Osswald H 2006. Adenosine and kidney function. Physiol Rev 86: 901-940.

Wang JY, Yin XX, Wu YM, Tang DQ, Gao YY, Wan MR 2006. Ginkgo biloba extract suppresses hypertrophy and extracellular matrix accumulation in rat mesangial cells. Acta Pharmacol Sin 27: 1222-1230.

Yale SH, Glurich I 2005. Analysis of the inhibitory potential of Ginkgo biloba, Echinacea purpurea, and Serenoa repens on the metabolic activity of cytochrome $\mathrm{P} 450$ 3A4, 2D6, and 2C9. J Altern Complem Med 11: 433439.

Yapar K, Cavusoglu K, Oruç E, Yalçin E 2010. Protective role of Ginkgo biloba against hepatotoxicity and nephrotoxicity in uranium-treated mice. J Med Food 13: 179-188.

Zlotogorski HA, Littner M 2004. Potential risks, adverse effects and drug interactions associated with herbal medicine in dental patients. Refuat Hapeh Vehashinayim 21: 25-41.

\section{*Correspondence}

Monica Dalmacio Silveira Campos Câmara

Programa de Pós-graduação em Ciências Médicas, Hospital Universitário Antônio Pedro, Universidade Federal Fluminense

Rua Marquês do Paraná, 303, 4º andar, Centro, 24033-900 Niterói-RJ, Brazil

Tel.: +552126299369 